\title{
Water Movement through a Pine-bark Substrate during Irrigation
}

Tyler C. Hoskins ${ }^{1}$ and James S. Owen, Jr. ${ }^{2,4}$

Department of Horticulture, Virginia Tech, Hampton Roads Agricultural Research and Extension Center, Virginia Beach, VA 23455

\author{
Alex X. Niemiera ${ }^{3}$ \\ Department of Horticulture, Virginia Tech, 301 Saunders Hall, Blacksburg, \\ VA 24061
}

Additional index words. leachate, preferential flow, root growth, solute transport, wetting front

\begin{abstract}
Regulatory and economic incentives to improve water and fertilizer use efficiency have prompted the nursery industry to seek new and advanced techniques for managing the production of ornamental crops. The development of best management practices, especially with regard to fertilizer and irrigation management, is largely based on research that looks at season-long trends in water and nutrient use. Understanding how water moves through a substrate during a single irrigation event may allow for the refinement of recommended best management practices that improve water and fertilizer use efficiency in container-grown plant production systems. Therefore, a study was conducted to characterize the movement of irrigation water at three growth stages $[4,9$, and 17 weeks after transplanting (WAT)] throughout the production cycle of Ilex crenata Thunb. 'Bennett's Compactum' that were container-grown in a bark-based substrate alongside fallow (i.e., without a plant) containers. Tensiometers were placed at three horizontal insertion depths and three vertical heights throughout the substrate profile to detect changes in matric potential $(\psi ; \mathrm{kPa})$, during individual irrigations. At $4 \mathrm{WAT}$, the preirrigation $\psi$ in the upper substrate profile was 12.3 times more negative (i.e., drier) than the substrate near the container's base and 6.0 times more negative than the middle of the container. This gradient was decreased at 9 and 17 WAT as roots grew into the lower portion of the substrate profile. On average, water began to drain from the base of containers $59.9 \mathrm{~s} \pm$ $1.0 \mathrm{SE}$ and $35.7 \mathrm{~s} \pm \mathbf{1 . 3} \mathrm{SE}$ after irrigation commencement for fallow containers and plantcontaining treatments, respectively, indicating channeling through the substrate of plantcontaining treatments. A pattern of plant water uptake by roots induced a gradient in the substrate's pre-irrigation moisture distribution, where portions of the substrate profile were relatively dry where plant roots had taken up water. Consequently, the application of water or fertilizer (i.e., fertigation) through irrigation has the potential to be highly inefficient if applied under dry substrate conditions where channeling may occur. Therefore, water application using cyclic irrigation or substrate moisture content (MC) thresholds (not letting MC fall below an undetermined threshold where channeling may occur) may improve water application efficiency. Furthermore, fertigation should occur when the substrate MC in the upper portion of the container is higher than the pre-irrigation MCs observed in this study to minimize the occurrence of channeling. The effect of root growth should also be taken into account when seeking the proper balance between preirrigation substrate $\mathrm{MC}$ and irrigation application rate to reduce the risk of unwanted channeling.
\end{abstract}

Minimizing the load of mineral nutrients that are leached from container-grown crops is a goal of both horticultural scientists and members of the industry for two reasons. First, leached mineral nutrients are no longer available for crop growth, and improvements in fertilizer use efficiency may help growers maintain profitability as fertilizer costs increase. Second, reducing the runoff nutrient load minimizes non-point source agrichemical contributions to local watersheds while simultaneously helping growers to comply with current or future regulatory standards such as the total maximum daily load limits for agrichemical contributions to the Chesapeake Bay watershed (Majsztrik and Lea-Cox, 2013). A set of best management practices (BMPs) (Bilderback et al.,
Controlled-release fertilizer performance is well understood as a result of season-long ( $\approx 4$ to 12 months) studies (Broschat and Moore, 2007; Cabrera, 1997) that use techniques like the pour-through procedure or effluent (leachate) collection to evaluate trends in nutrient release. This knowledge enables growers to make informed decisions regarding irrigation and fertilizer management in an effort to improve crop quality and reduce nutrient loss through leaching. However, considerably less is known about nutrient leaching trends on a short time scale, i.e., how water and fertilizers move through and leach from a soilless substrate during and immediately after an irrigation event. Developing this knowledge may allow for the refinement of production practices (e.g., irrigation, fertilizer use, substrate selection, etc.) that lead to improved water and nutrient use efficiency.

Research on water and solute transport in soils (Beven and Germann, 2013; Mohammadi et al., 2009; Russo, 1993) provides a good foundation for understanding soilless systems. However, as a result of the substantial differences in physical properties between soils and soilless substrates, an independent body of research on water and solute transport is warranted to develop a more direct and thorough understanding of water and solute transport in soilless systems. Physical properties of the pine-bark and sand blends commonly used in the mid-Atlantic and southeastern U.S. nursery industry for the production of woody ornamentals (similar to the substrate used in this study) consists predominantly of large, low-density particles of organic origin. Consequently, substrates are highly porous and of low bulk density (Drzal et al., 1999). Fields et al. (2014) evaluated the wettability (rehydration efficiency) of pine-bark and found that the initial substrate $\mathrm{MC}$ and use of wetting agents had a significant impact on the number of hydration events that it takes to rewet a pinebark substrate. It stands to reason that the pre-irrigation substrate MC would affect the movement and retention of water during an irrigation event. Therefore, characterizing how water moves through soilless substrates during irrigation is warranted, because it may lead to improved production practices that maximize water application efficiency (i.e., substrate retention of applied water).

An understanding of how water flows through a bark-based substrate also necessitates an investigation of the effect of root growth on water movement. Altland et al. (2011) demonstrated that plant roots will decrease air space and increase container capacity (CC), an effect that has been attributed to roots growing into and occupying pore spaces as well as the decomposition of organic substrate components. Gish and Jury (1983) observed that in loamy sand columns, an infiltrating chloride tracer solution applied to columns under pre-established, steady-state flow conditions moved through the column with less dispersion (i.e., more evenly) in treatments containing a wheat plant than a fallow column. They postulated that roots 
grew into large pore spaces and effectively created a homogenous pore size distribution that reduced the preferential flow of water through large pores and created a more uniform network of flow paths. However, their experiments were conducted under steady-state flow conditions, not under irrigation conditions (i.e., when the soil or substrate is of relatively low water content). Nash and Laiche (1981) assessed the hydraulic conductivity (HC) of water moving through bark, peat, and sand-based horticultural substrates in which ryegrass was grown. They reported high and variable $\mathrm{HCs}$ that generally ranged from 1.0 to $4.5 \mathrm{~cm} \cdot \mathrm{min}^{-1}$ and in extreme cases reported values of $26 \mathrm{~cm} \cdot \mathrm{min}^{-1}$. They theorized that roots that were concentrated near the substrate surface and along container walls may have caused channeling along container walls and lead to localized high $\mathrm{HC}$ values. Johnson and Lehmann (2006) discussed how, in shrinkswell soils, live roots that compress adjacent soil and decomposed roots allow for the preferential flow of infiltrating water through root-generated paths. Selker (1996) discussed the concept of preferential flow under field conditions and highlighted three types of preferential flow as 1) fingered flow (i.e., fingers or channels create uneven flow paths through coarse textured soils); 2) macropore flow (i.e., water flow is dominated by large over small pores); and 3) funnel flow (i.e., different textural layers redirect the flow of water). These flow types may provide insight into how applied irrigation water moves through soilless substrates. However, a more direct study of preferential flow path formation in common horticultural soilless substrates would be useful when developing BMPs that maximize irrigation and fertilizer efficiency.

This research is focused on characterizing the movement of irrigation water throughout a 17-week production cycle using Ilex crenata Thunb. 'Bennett's Compactum' grown in 2.7-L nursery containers and a bark-based substrate. The objectives of this study were 1)

Received for publication 13 May 2014. Accepted for publication 17 Sept. 2014.

This publication is a portion of a thesis submitted by Tyler C. Hoskins in partial fulfillment of the degree of Master of Science.

Funding for this work was provided in part by the Virginia Nursery and Landscape Association, Virginia Agricultural Council, Virginia Agricultural Experiment Station and the Hatch program of the National Institute of Food and Agriculture, U.S. Department of Agriculture.

Special thanks to Julie Brindley for technical assistance, Drs. Zach Easton and Michelle Frey for input and guidance.

Trade or brand names used in this publication do not constitute a guarantee or warranty of the product by Virginia Tech and do not imply its approval to the exclusion of other products or vendors that also may be suitable.

${ }^{1}$ Graduate Research Assistant.

${ }^{2}$ Assistant Professor.

${ }^{3}$ Professor.

${ }^{4}$ To whom reprint requests should be addressed; e-mail jim.owen@vt.edu. to evaluate the patterns in which water moves through a pine-bark based substrate at different depths in the container profile; and 2) to determine the subsequent effect of root growth on water movement.

\section{Materials and Methods}

Experimental design. The experiment was a four (sampling interval) $\times$ three (height of sensor placement in container profile) factorial with five horizontal sensor insertion depths within each profile height using a completely randomized design with five replicates. Three of the sampling intervals were plant-containing treatments that spanned several degrees of root growth $(4,9$, and 17 WAT). One treatment was left fallow (i.e., not containing a plant) to evaluate the flow of water without roots. Water movement was evaluated at three heights in the container's vertical profile and five depths in the container's horizontal profile (Table 1).

On 29 May, 2013, uniform Ilex crenata 'Bennett's Compactum' liners (substrate removed from roots) were potted (two liners per container $)$ into $2.7-\mathrm{L}(17.8 \mathrm{~cm}$ tall, $15.7 \mathrm{~cm}$ upper diameter) nursery containers (Product no. NRT0T1G3; Myers industries, Middlefield, $\mathrm{OH}$ ) using a 9 part bark:1 part sand (by vol.) substrate amended with 1.8 $\mathrm{kg} \cdot \mathrm{m}^{-3}$ crushed dolomitic lime (Rockydale Quarries Corp., Roanoke, VA) and 1.8 $\mathrm{kg} \cdot \mathrm{m}^{-3}$ pelletized dolomitic lime (Kelly's Limestone LLC., Kirksville, MO). Sixty containers were potted with plants (only 45 were needed for use in the study), which afforded researchers the opportunity to exclude any plants that displayed abnormal growth or had died. An additional 15 containers were potted and left fallow (i.e., without plants) for use as a control treatment. Each container was filled to the rim with substrate, leveled, and tapped three times to the settle the substrate, which resulted in $2.5 \mathrm{~cm}$ of head space. Physical properties (Table 2) were determined using the North Carolina State University porometer procedure (Fonteno and Harden, 2003). Particle size distribution (percent by weight), as determined by sieving oven-dried substrate using a 5-min mechanical agitation (278 oscillations per minute), with a RX-29 Ro-Tap shaker (W.S. Tyler Industrial Group, Mentor, $\mathrm{OH}$ ) was as follows: greater than $6.3 \mathrm{~mm}=8.0 ; 6.3$ to $2 \mathrm{~mm}=27.6 ; 2$ to $0.71 \mathrm{~mm}=37.9$; less than $0.71 \mathrm{~mm}=26.5$. Each container was topdressed with $9 \mathrm{~g}$ of a $16 \mathrm{~N}-2.6 \mathrm{P}-9.1 \mathrm{~K} ; 7.9 \% \mathrm{~N}-\mathrm{NO}_{3}, 8.4 \% \mathrm{~N}-\mathrm{NH}_{4}+$ micronutrient CRF (Harrell's 16-6-11, 5 to
6 month longevity, Lakeland, FL). Beginning $10 \mathrm{WAT}$, all remaining plants were liquid-fed weekly with $200 \mathrm{~mL}$ of $20 \mathrm{~N}-8.7 \mathrm{P}-16.6 \mathrm{~K}$ water-soluble fertilizer (Peters 20-20-20; JR Peters Inc., Allentown, PA) mixed to a concentration of $238 \mathrm{mg} \cdot \mathrm{L}^{-1} \mathrm{~N}$ to promote additional growth. Fallow containers (i.e., containing no plant) were also potted as a control. At potting, all plants were pruned to a uniform baseline canopy architecture (height $=14 \mathrm{~cm} \pm 0.9 \mathrm{SE}$; width $=14.6 \pm 1.1$ $\mathrm{SE} ;$ perpendicular width $=12.4 \mathrm{~cm} \pm 1.3 \mathrm{SE} ; \mathrm{n}=$ 5). Plants were grown on an outdoor gravel bed at the Hampton Roads Agricultural Research and Extension Center in Virginia Beach, VA. All treatments received overhead irrigation $\left(1.27 \mathrm{~cm} \cdot \mathrm{h}^{-3}\right)$ every other day and were managed to maintain or exceed a target leaching fraction (vol. leached/vol. applied) of 0.1 .

Data were collected at three harvest intervals throughout the season, 4, 9, and 17 WAT. As a result of the effect of canopy architecture on irrigation water interception (Million et al., 2010), all plants were pruned to a width and height of $15.7 \mathrm{~cm}$ (container diameter) 1 week before each harvest interval to minimize any impact of canopy architecture on water application rate or volume. At each harvest interval, 15 containers were brought indoors and the substrate was allowed to dry to an average, gravimetrically determined, volumetric water content (VWC) of $31.9 \% \pm 0.004 \mathrm{SE}$ $(\mathrm{n}=60)$. After reaching the target VWC, each container was prepared for irrigation in a custom irrigation platform (Fig. 1), during which substrate $\psi$ and the time which drainage began was measured. Of the 15 containers used at each harvest interval, $\psi$ was measured at one of three heights in the container profile (five replications per height): upper, mid, and low height $(12.7,7.6$, and $2.5 \mathrm{~cm}$ from the container base, respectively). At each profile height, five T5 tensiometers (UMS, Munich, Germany) were horizontally placed every $72^{\circ}$ around the circumference of that container (Fig. 2) and were inserted to a specified depth (Table 1) that varied proportionately with the taper of the container but were evenly distributed between the center of the container and the wall at each height. Each container was prepared for tensiometer installation by drilling a $5-\mathrm{mm}$ hole in the container wall and boring a horizontal pilot hole into the substrate using a bore provided by UMS with the tensiometers. All holes were bored $5 \mathrm{~mm}$ short of the final sensor installation depth (Table 1). This method left $5 \mathrm{~mm}$ of minimally altered substrate in which the tensiometer tip would nest, improving sensor contact

Table 1. Tensiometer insertion depths ( $\mathrm{cm}$ from the center of the horizontal container profile) at each height in the vertical container profile.

\begin{tabular}{lcccccc}
\hline & \multicolumn{5}{c}{ Sensor position $^{\mathrm{z}}$} & Container radius $^{\mathrm{x}}$ \\
\cline { 2 - 6 } Vertical position $^{\mathrm{y}}$ & 1 & 2 & 3 & 4 & 5 & 7.1 \\
\hline Upper $(12.7 \mathrm{~cm})$ & 0.0 & 1.5 & 2.9 & 4.4 & 5.8 & 6.7 \\
Mid $(7.6 \mathrm{~cm})$ & 0.0 & 1.4 & 2.7 & 4.1 & 5.4 & 6.3 \\
Low $(2.5 \mathrm{~cm})$ & 0.0 & 1.3 & 2.5 & 3.8 & 5.0 & \\
\hline
\end{tabular}

zPositions correspond to those in Figure 2B.

${ }^{\mathrm{y}}$ Distance from the base of the container.

${ }^{\mathrm{x}}$ Container radius differs at each vertical profile height as a result of the taper of the container and determines the horizontal distribution of the sensors at the given vertical profile height. 
with the substrate. Containers were then placed in the irrigation platform and tensiometers were inserted into the substrate and connected to a CR3000 data logger and AM16/32A multiplexer (Campbell Scientific, Inc., Logan, UT) programmed to collect one measurement from each sensor every second. After installation, tensiometers were allowed to equilibrate until they provided a steady baseline measurement, at which point containers were irrigated with deionized water through a constant head (i.e., pressure) diffuser mounted $27 \mathrm{~cm}$ above the substrate surface. Irrigation was applied at a rate of 300 $\mathrm{mL} \cdot \mathrm{min}^{-1}$, which is comparable to a $19-\mathrm{L} \cdot \mathrm{h}^{-1}$ spray stake but inherently faster that most overhead irrigation systems. Irrigation ended

Table 2. Physical properties for a substrate comprised of 9 parts pine-bark and 1 part sand (by vol.).

\begin{tabular}{lccc}
\hline $\mathrm{D}_{\mathrm{b}}$ & $\mathrm{TP}$ & $\mathrm{CC}$ & $\mathrm{AS}$ \\
\hline 0.325 & 78.7 & 52.3 & 26.4 \\
\hline $\mathrm{D}_{\mathrm{b}}=$ Bulk density, & $\mathrm{g} \cdot \mathrm{cc}^{-1} ;$ & $\mathrm{TP}=$ total & porosity \\
percent of substrate vol. comprised of pores; & $\mathrm{CC}=$ \\
container capacity, percent of substrate vol. comprised \\
of water after free drainage; $\mathrm{AS}=$ air space, percent of \\
substrate vol. comprised of air at $\mathrm{CC}$.
\end{tabular}
AS 西 . the moisture distribution throughout the container and determine the time at which water arrived at individual sensors. Moisture distribution was assessed using the matric potential at the time irrigation began $\left(\psi_{\mathrm{o}}\right)$. For the

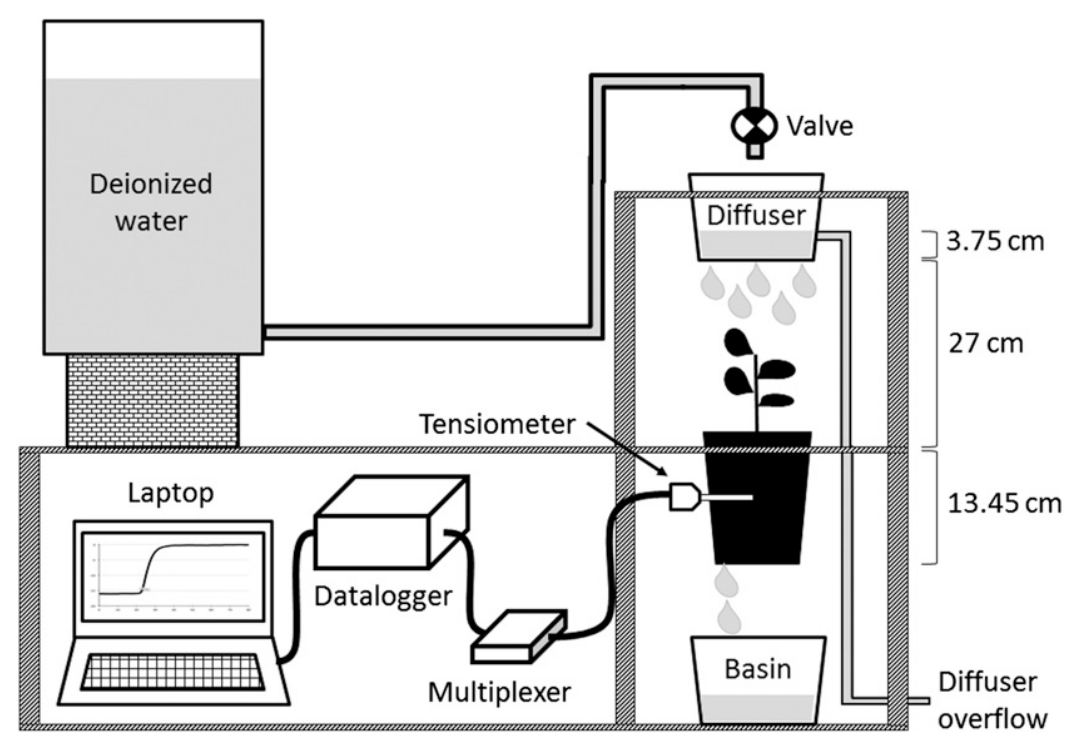

Fig. 1. Physical setup of the irrigation platform depicting the application of deionized irrigation water through a diffuser and the flow of real-time substrate matric potential data from tensiometers to a laptop.

\section{A) Vertical distribution}

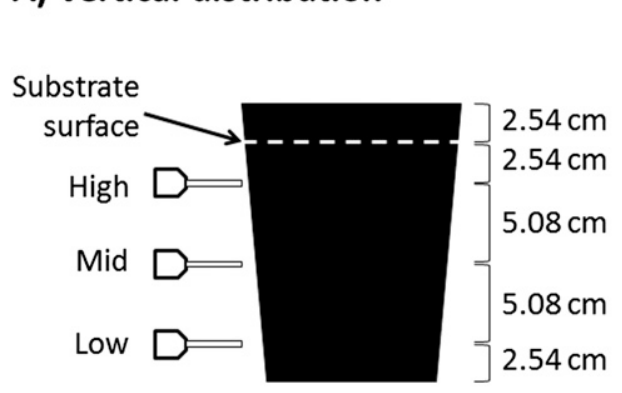

\section{B) Horizontal distribution}

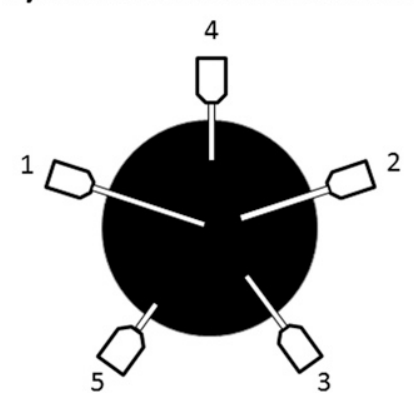

Fig. 2. (A) Distribution of tensiometers in the vertical container profile relative to the container size and substrate level. (B) Overhead view of a container showing the horizontal distribution of tensiometers. Insertion depths correspond to those stated in Table 2. vertical moisture distribution, $\psi_{\mathrm{o}}$ from all five sensors at the low, mid, or upper profile heights $(2.5,7.6$, or $12.7 \mathrm{~cm}$, respectively) were pooled. As shown in Figure 3, the time (seconds after commencement of irrigation) at which water arrived at individual tensiometers was calculated using a procedure adapted from Germann and Hensel (2006) in which a linear regression line was fitted to the baseline $\psi$, and a second line was fitted to the slope induced by water arrival. The intersection of these two lines was considered the time at which water arrived at a given sensor. Additionally, the time at which water was first observed to drain from containers during irrigation was also recorded. These arrival times (tensiometer and drainage) were normalized by converting to a rate by dividing the linear distance that water would travel (substrate surface to tensiometer or container base) by the time it was calculated to arrive at a given location. These rates were compared at different locations in the container and allowed the authors to make inferences about water movement at different locations throughout the container.

Moisture distribution and the calculated rate of water arrival data were subjected to analysis of variance $(\alpha=0.1)$ (Marini, 1999) and means separation by way of Tukey's honestly significant difference or Tukey-Kramer's. All data were processed using JMP ${ }^{\circledR}$ Pro Version 10.0.2 (SAS Institute Inc., Cary, NC).

\section{Results and Discussion}

Moisture distribution. Analysis of $\psi$ before the onset of irrigation reveals a vertically distributed moisture gradient, where the substrate is driest at the top of the container and wettest at the base (Table 4), confirming trends observed by Owen and Altland (2008). This gradient (Table 5; presented as a $\psi$ ratio between different profile heights) is of greatest magnitude between the upper and lower profile heights (12.7 and $2.5 \mathrm{~cm}$ from the container base, respectively) at 4 WAT. A similar trend was observed between the upper and $\mathrm{mid}(7.60 \mathrm{~cm}$ from container base) profile heights, although the magnitude of these gradients is less than the observed gradient between upper and low profile heights. A much smaller moisture gradient was observed in the fallow treatment ( 0 WAT) and is likely the result of the combined effect of surface evaporation and the pooling of gravitational water in the base of the container. The moisture distribution of plant-containing treatments $(4,9$, and 17 WAT) followed general trends in root growth. At 4 WAT, roots had grown to a sub-surface depth $8.89 \mathrm{~cm}$ (Table 3). Consequently, most of the plant-water uptake occurred above this $8.89-\mathrm{cm}$ root depth, leading to a concentrated dry region in the upper substrate profile and a steeper observed moisture gradient than at 9 or 17 WAT. As roots grew deeper into the substrate at 9 and 17 WAT, the total portion of the substrate profile that water was taken up by the plant had expanded, and the moisture gradient between the relatively dry 
upper regions and relatively wet lower regions decreased. This indicates that a seasonal increase in root depth (and proportionate root mass) was associated with a more uniform pattern of water uptake throughout the container's vertical profile.

There was only a minimal horizontal moisture gradient at each vertical profile height (data not shown). Differences were only observed at the upper profile height during the early (4 WAT) and midseason ( 9 WAT) harvest intervals. Here, the substrate was driest in the center of the container and wetter near the container wall. Although not measured, lateral root distribution and subsequent pattern in water uptake possibly caused this phenomenon, similar to how root depth affected the aforementioned vertical moisture distribution.

Wetting front movement. Water was observed to begin draining from the base of

Table 3. Root length and dry weight of Ilex crenata 'Bennett's Compactum' grown in a substratefilled 2.7-L nursery container throughout a 17 week period.

\begin{tabular}{lcc}
\hline WAT $^{z}$ & Root depth $(\mathrm{cm})$ & Root dry wt $(\mathrm{g})$ \\
\hline 4 & $8.89 \mathrm{a}^{\mathrm{y}}$ & $1.61 \mathrm{a}$ \\
9 & $12.11 \mathrm{~b}$ & $3.08 \mathrm{~b}$ \\
17 & $14.67 \mathrm{c}$ & $6.26 \mathrm{c}$ \\
\hline
\end{tabular}

${ }^{2}$ WAT $=$ weeks after transplant. The 0 WAT treatment is not included as this treatment is for fallow containers.

${ }^{\mathrm{y}}$ Means within column not sharing the same letter are significantly different using Tukey's honestly significant difference $(P \leq 0.1)$.

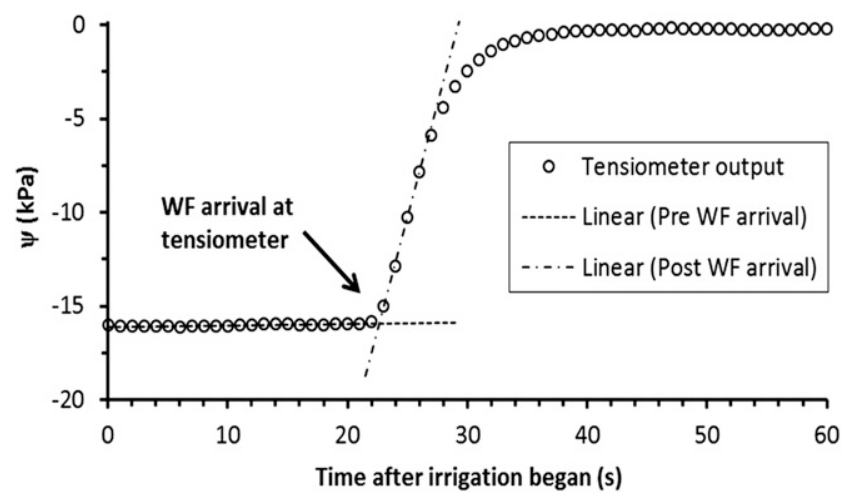

Fig. 3. Example of how substrate matric potential at the time when irrigation began $\left(\psi_{\mathrm{o}}\right)$ and wetting front (WF) arrival are determined. $\psi_{\mathrm{o}}$ is based on the first $\psi$ measurement (i.e., time $=0 \mathrm{~s}$ ). WF arrival is calculated from the intersection of the pre- and post-WF arrival linear regressions. In this case, the WF arrives $23 \mathrm{~s}$ after irrigation began. containers $59.9 \mathrm{~s} \pm 1.0 \mathrm{SE}$ and $35.7 \mathrm{~s} \pm 1.3 \mathrm{SE}$ after irrigation commencement for fallow and plant-containing (pooled average of 4, 9 , and 17 WAT) treatments, respectively. The observed drainage times contributed to the highest calculated rate of water movement occurring at the base of the container (based on the time at which water was first observed to drain) for each plant-containing treatment WAT at the low profile height where the calculated rate was similar to the rate at the container base (Table 4). In comparison, there were no differences in the calculated rate of water movement between any of the profile heights and the container base for the fallow (0 WAT) treatment (Table 4). Collectively, these findings suggest that water channeled through the substrate or along container walls in plant-containing treatments and progressed somewhat evenly through the substrate of the fallow treatment

Among the upper, mid, and lower profile heights of each plant-containing treatment (4, 9 , and 17 WAT), the rate of water movement was calculated to be highest in the lower profile and lowest in the upper profile (Table 4). This general trend persisted throughout the season. Initially, these differences in the calculated rates of water movement may seem counterintuitive. However, the relationship between substrate MC and the width and speed of an infiltrating finger (channel of water) may help to explain these findings. Bauters et al. (2000) and Liu et al. (1994) demonstrated that, in sands, an infiltrating $(4,9$, and 17 WAT) with the exception of 4 finger or channel of water will be relatively narrow and fast-moving at low MCs and will be relatively wide and slow-moving at high MCs. Applied to the findings of this study, it is likely that in the upper portion of the container profile, where the substrate is relatively dry, narrow and fast-moving channels develop that may bypass the tensiometers at that height. When that channel subsequently reaches the lower, relatively wet profile heights, it becomes more diffuse and progresses slowly.

For a bypassed, upper-profile tensiometer to detect the arrival of water, it would then require a secondary mechanism. Such possibilities include 1) the formation of a new channel that directly contacts the tensiometer; 2) lateral redistribution of water from an adjacent channel; or 3) backfilling from a lower region in the container profile that begins after a channel has reached the base of the container. In any of these scenarios, the original channel or finger may cross the horizontal plane at the upper profile height before water reaches the tensiometer through one of the secondary mechanisms at a later time. The net effect is an inflation of the denominator (time) in the rate of water movement calculation, hence a slower calculated rate in the upper profile. These fast-moving channels in the upper profile would likely reach the lower substrate profile heights quickly, where they are likely to be more diffuse and make contact with tensiometers more evenly.

The observed seasonal increase in root growth and the subsequent change in moisture distribution between plant-containing treatments did not impact the previously discussed patterns of water movement (inferred from calculated water velocities) at any of the profile heights. The most substantial difference was between the fallow and any plant-containing treatment. However, although roots had grown to the full substrate depth by the end of the study, roots had not totally occupied the entire substrate volume; hence, the state of roots in the container was not considered pot-bound after 17 weeks. Allowing more time for roots to proliferate in the lower profile heights may have a meaningful impact on water movement in future studies with regard to crops late in their production cycle.

The increase in root mass throughout the season (Table 3 ) likely reduced the total pore

Table 4. Substrate matric potential at the onset of irrigation $\left(\psi_{\mathrm{o}} ; \mathrm{kPa}\right)$ and calculated rate of water movement $\left(\mathrm{v} ; \mathrm{cm} \cdot \mathrm{s}^{-1}\right)$ at four different heights along the vertical profile of a substrate-filled 2.7-L nursery container throughout a 17 -week period.

\begin{tabular}{|c|c|c|c|c|c|c|c|c|}
\hline \multirow[b]{3}{*}{ Distance from base $(\mathrm{cm})$} & \multicolumn{8}{|c|}{ Production phase $\left(\right.$ WAT $\left.^{\mathrm{z}}\right)$ of Ilex crenata Bennett's Compactum } \\
\hline & \multicolumn{2}{|c|}{$0^{\mathrm{y}}$} & \multicolumn{2}{|c|}{4} & \multicolumn{2}{|c|}{9} & \multicolumn{2}{|c|}{17} \\
\hline & $\psi_{\mathrm{o}}$ & $\mathrm{V}$ & $\psi_{\mathrm{o}}$ & $\mathrm{V}$ & $\psi_{\mathrm{o}}$ & $\mathrm{V}$ & $\psi_{\mathrm{o}}$ & $\mathrm{V}$ \\
\hline$\overline{12.70}$ & $-6.44 \mathrm{a} \mathrm{A}^{\mathrm{x}}$ & $0.23 \mathrm{a}$ & $-23.28 \mathrm{~b} \mathrm{~A}$ & $0.13 \mathrm{~b} \mathrm{~A}$ & $-22.92 \mathrm{~b} \mathrm{~A}$ & $0.13 \mathrm{~b} \mathrm{~A}$ & $-27.67 \mathrm{~b} \mathrm{~A}$ & $0.13 \mathrm{~b} \mathrm{~A}$ \\
\hline 7.62 & -3.97 a B & 0.24 & -4.05 a B & $0.24 \mathrm{AB}$ & $-11.08 \mathrm{~b} \mathrm{~B}$ & $0.23 \mathrm{~B}$ & -17.59 c B & $0.21 \mathrm{~B}$ \\
\hline 2.54 & -2.47 a $C$ & $0.20 \mathrm{a}$ & -1.84 a B & $0.34 \mathrm{~b} \mathrm{BC}$ & $-6.07 \mathrm{~b} \mathrm{C}$ & $0.29 \mathrm{ab} \mathrm{B}$ & -13.85 c C & $0.28 \mathrm{ab} \mathrm{B}$ \\
\hline $0.00^{\mathrm{w}}$ & - & $0.25 \mathrm{a}$ & - & $0.48 \mathrm{~b} \mathrm{C}$ & - & $0.42 \mathrm{~b} \mathrm{C}$ & - & $0.44 \mathrm{~b} \mathrm{C}$ \\
\hline
\end{tabular}

${ }^{\mathrm{z}}$ Weeks after transplant.

${ }^{\mathrm{y}} 0$ WAT signifies a fallow container.

${ }^{\mathrm{x}} \psi$ or $\mathrm{v}$ means not sharing the same lower-case letter within rows, or upper-case letters within columns, are significantly different according to Tukey-Kramer's honestly significant difference $(P<0.1)$. Any row or column without the respective lower or upper-case letter indicates no significant differences between means. ${ }^{w}$ Base of container; $\psi$ not measured at container base; $v$ is based on the time at which drainage began. 
Table 5. Matric potential ratios between the top, mid, and low $(12.7,7.6$, and $2.5 \mathrm{~cm}$ from the container base, respectively) profile heights for Ilex crenata 'Bennett's Compactum' grown in a substrate-filled 2.7-L nursery container throughout a 17 -week period.

\begin{tabular}{lccc}
\hline & \multicolumn{3}{c}{ Profile ht comparison } \\
\cline { 2 - 4 } WAT $^{\mathrm{z}}$ & Upper vs. low & Upper vs. mid & Mid vs. low \\
\hline $0^{\mathrm{y}}$ & $2.8 \mathrm{~A} \mathrm{a}^{\mathrm{x}}$ & $1.7 \mathrm{~A} \mathrm{~b}$ & $1.8 \mathrm{~b}$ \\
4 & $12.3 \mathrm{~B} \mathrm{a}$ & $6.0 \mathrm{~B} \mathrm{~b}$ & $2.0 \mathrm{~b}$ \\
9 & $4.5 \mathrm{~A} \mathrm{a}$ & $2.6 \mathrm{~A} \mathrm{~b}$ & $2.2 \mathrm{~b}$ \\
17 & $2.1 \mathrm{~A} \mathrm{a}$ & $2.1 \mathrm{~A} \mathrm{ab}$ & $1.4 \mathrm{~b}$ \\
\hline
\end{tabular}

${ }^{\mathrm{z}}$ Weeks after transplant.

y0 WAT signifies a fallow container.

${ }^{\mathrm{x}}$ Means not sharing the same lower-case letter within row, or upper-case letter within column, are significantly different according to Tukey's honestly significant difference $(P \leq 0.1)$. Any row or column without the respective lower or upper-case letter indicates no significant differences between means.

space in the container as roots grew into and occupied existing pore spaces. This effect, in combination with the possible settling (or rearrangement) and decomposition (Nash and Laiche, 1981) of substrate particles, may have changed the substrate's physical properties (reduced volume, reduced porosity, reduced particle size, increased waterholding capacity) and affected water movement. Although the scope of this study was delimited to one species and one substrate, further research that elaborates on the effect of substrate physical properties and speciesspecific root architectures on water movement patterns may provide valuable insight that enhances substrate moisture management.

\section{Conclusions}

The results of this study demonstrate the tendency for water to channel through nursery containers under our experimental conditions. Irrigation water may channel through portions of the substrate, leading to an uneven post-irrigation water distribution and unnecessary loss of water and leaching of dissolved fertilizer salts. This may be of increasing concern when applying fertilizer through irrigation water (i.e., fertigation), because applied fertilizers may quickly leach from a substrate and not reach the entire root zone. If a crop is to be fertigated, it would be most effective to do so when the substrate is at or near CC and to apply only the quantity of water needed to displace the volume of water held by the substrate at $\mathrm{CC}$.

As a result of the impact of root growth on water uptake and the subsequent pre-irrigation substrate moisture distribution at different times throughout a production season, caution should be exercised when using substrate weight as an indicator of when to irrigate a newly planted crop. If the lower portion of a substrate profile is at a high MC, the container may still be heavy despite the need to irrigate the upper profile, where the roots reside.

This research raises questions about how irrigation management practices such as application method, application rate, and substrate $\mathrm{MC}$ at the time of irrigation affect the water movement. Applying water at a high rate to a dry substrate may lead to unnecessary leaching of water and nutrients. Therefore, additional research is warranted to determine the optimal balance between MC and water application rate to minimize leaching without perpetually keeping the substrate too wet. If a crop is to be irrigated when dry, the use of cyclic irrigation (i.e., fractioning the total irrigation volume into several pulses or cycles, applied throughout the day) may reduce the risk of unwanted leaching. The first cycle may channel through a portion of the substrate but can laterally diffuse between cycles to reduce the amount of channeling that occurs in later cycles. Lastly, the use of surfactants deserves additional research to determine if their use may increase the width of a channel infiltrating through a dry substrate and improve wetting efficiency.

\section{Literature Cited}

Altland, J.E., J.S. Owen, and M.Z. Gabriel. 2011 Influence of pumice and plant roots on substrate physical properties over time. HortTechnology 21:554-557.

Bauters, T.W.J., D.A. DiCarlo, T.S. Steenhuis, and J.Y. Parlange. 2000. Soil water content dependent wetting front characteristics in sands. J. Hydrol. (Amst.) 231:244-254.

Beven, K. and P. Germann. 2013. Macropores and water flow in soils revisited. Water Resour. Res. 49:3071-3092.

Bilderback, T., C. Boyer, M. Chappell, G. Fain, D Fare, C. Gilliam, B.E. Jackson, J. Lea-Cox, A.V. LeBude, A. Niemiera, J. Owen, J. Ruter, K. Tilt, S. Warren, S. White, T. Whitewell, R. Wright, and T. Yeager. 2013. Best management practices: Guide for producing nursery crops. 3rd Ed. Southern Nursery Association, Inc., Acworth, GA. 3 Mar. 2014. <http://contents. sna.org/bmpv30.html>.

Broschat, T.K. and K.K. Moore. 2007. Release rates of ammonium-nitrogen, nitrate-nitrogen, phosphorus, potassium, magnesium, iron, and manganese from seven controlled-release fertilizers. Commun. Soil Sci. Plant Anal. 38:843850.

Cabrera, R.I. 1997. Comparative evaluation of nitrogen release patterns from controlledrelease fertilizers by nitrogen leaching analysis. HortScience 32:669-673.

Dennis, J.R., R.G. Lopez, B.K. Behe, C.R. Hall, C.Y. Yue, and B.L. Campbell. 2010. Sustainable production practices adopted by greenhouse and nursery plant growers. HortScience 45:1232-1237.
Drzal, M.S., W.C. Fonteno, and D.K. Cassel. 1999. Pore fraction analysis: A new tool for substrate testing. Acta Hort. 481:43-54.

Fields, J.S., W.C. Fonteno, and B.E. Jackson. 2014 Hydration efficiency of traditional and alternative greenhouse substrate components. HortScience 49:336-342.

Fonteno, W.C. and C.T. Harden. 2003. Procedures for determining physical properties of horticultural substrates using the NCSU porometer. Hort. Substrates Lab., Raleigh, NC.

Garber, M.P., J.A. Ruter, J.T. Midcap, and K. Bondari. 2002. Survey of container nursery irrigation practices in Georgia. HortTechnology 12:727-731.

Germann, P.F. and D. Hensel. 2006. Poiseuille flow geometry inferred from velocities of wetting fronts in soils. Vadose Zone $\mathrm{J}$. 5:867-876.

Gish, T.J. and W.A. Jury. 1983. Effect of plantroots and root channels on solute transport. Trans. Amer. Soc. Agr. Eng. 26:440.

Johnson, M.S. and J. Lehmann. 2006. Doublefunneling of trees: Stemflow and rootinduced preferential flow. Ecoscience 13: 324-333.

Liu, Y.P., T.S. Steenhuis, and J.Y. Parlange. 1994. Formation and persistence of fingered flowfields in coarse-grained soils under different moisture contents. J. Hydrol. (Amst.) 159:187195.

Majsztrik, J.C. and J.D. Lea-Cox. 2013. Water quality regulations in the Chesapeake Bay: Working to more precisely estimate nutrient loading rates and incentivize best management practices in the nursery and greenhouse industry. HortScience 48:1097-1102.

Mangiafico, S.S., J. Newman, M. Mochizuki, D. Zurawski, D.J. Merhaut, and B. Faber. 2010. Nurseries surveyed in southern California adopt best practices for water quality. Calif. Agr. 64:26-30.

Marini, R.P. 1999. Are nonsignificant differences really not significant? HortScience 34:761762

Million, J.B., T.H. Yeager, and J.P. Albano. 2010. Evapotranspiration-based irrigation scheduling for container-grown Viburnum odoratissimum (L.) Ker Gawl. HortScience 45:1741-1746.

Mohammadi, M.H., M.R. Neishabouri, and H. Rafahi. 2009. Predicting the solute breakthrough curve from soil hydraulic properties. Soil Sci. 174:165-173.

Nash, V.E. and A.J. Laiche. 1981. Changes in the characteristics of potting media with time. Commun. Soil Sci. Plant Anal. 12:1011-1020.

Owen, J.S., Jr. and J.E. Altland. 2008. Container height and douglas fir bark texture affect substrate physical properties. HortScience 43:505508.

Russo, D.D.G. 1993. Water flow and solute transport in soils: Developments and applications. Springer-Verlag, Berlin, Germany; New York, NY.

Schoene, G., T. Yeager, and D. Haman. 2006. Survey of container nursery irrigation practices in west-central Florida: An educational opportunity. HortTechnology 16:682-685.

Selker, J.S. 1996. Applying preferential flow concepts to horticultural water management. HortTechnology 6:107-110.

Wilson, P.C. and J.P. Albano. 2011. Impact of fertigation versus controlled-release fertilizer formulations on nitrate concentrations in nursery drainage water. HortTechnology 21:176-180. 